\title{
Gambaran Pelayanan Terintegrasi dan Komprehensif pada Balita Bawah Garis Merah di Puskesmas Soreang
}

\author{
Lisbeth Maria Laurentia ${ }^{1}$, Elsa Pudji Setiawati ${ }^{2}$, Dadang Hudaya Somasetia ${ }^{3}$, Dany Hilmanto $^{3}$ \\ ${ }^{1}$ Fakultas Kedokteran, Universitas Padjadjaran \\ ${ }^{2}$ Departemen Ilmu Kesehatan Masyarakat, Fakultas Kedokteran Universitas Padjadjaran \\ ${ }^{3}$ Departemen Ilmu Kesehatan Anak, Fakultas Kedokteran Universitas Padjadjaran/Rumah Sakit Umum Pusat \\ Hasan Sadikin Bandung, Indonesia
}

\begin{abstract}
Abstrak
Pelayanan balita Bawah Garis Merah (BGM) seharusnya diberikan secara terintegrasi dan komprehensif supaya mencegah terjadinya gizi kurang/buruk berulang maupun penyakit infeksi pada anak. Penelitian ini bertujuan mengeksplorasi gambaran pelayanan terintegrasi dan komprehensif berdasarkan standar Kementerian Kesehatan Republik Indonesia serta faktor yang memengaruhi pelayanan. Penelitian kualitatif: pelayanan terintegrasi dan komprehensif balita BGM berdasarkan standar Kementerian Kesehatan Republik Indonesia, dilakukan mulai dari September sampai November 2016 di rumah responden, posyandu/polindes dan Puskesmas Soreang. Data diambil dari 18 responden (ibu balita BGM, kader, bidan, petugas gizi, dokter dan Kepala Puskesmas Soreang) dengan metode purposive sampling. Pengumpulan data dilakukan dengan wawancara mendalam. Validasi data menggunakan teknik triangulasi data. Pelayanan terintegrasi dan komprehensif balita BGM di Puskesmas Soreang terdiri dari pelayanan promotif dan preventif. Pelayanan promotif berupa edukasi makanan dan kesehatan anak. Pelayanan preventif berupa pemberitahuan berat badan anak kurang, edukasi pola makanan, penimbangan, rujukan ke petugas kesehatan dan pemberian makanan tambahan. Namun belum semua ibu balita BGM menerima penyuluhan balita BGM dan konseling nutrisi dengan jelas dari petugas gizi/dokter karena belum sepenuhnya dilakukan rujuk dari posyandu ke puskesmas. Pelayanan kuratif di Puskesmas Soreang untuk balita BGM seperti dalam Bagan Tatalaksana Anak Gizi Buruk Kementerian Kesehatan Republik Indonesia Tahun 2011 belum berjalan.
\end{abstract}

Kata Kunci : Balita, Gizi Kurang, Pelayanan terintergrasi dan komprehensif, Preventif, Promotif

\section{Illustration of Integrated and Comprehensive Health Services for Under Five Years Children with Below Red Line at Puskesmas Soreang}

\begin{abstract}
Under five years children with below red line (BRL) have to be treated with integrated and comprehensive health services in order to prevent mild to severe malnutrition repeatedly or infection disease on children. The aim of the study is to explore the illustration of integrated and comprehensive based on Indonesian Health Ministry's standard with the factors that affect health service. A qualitative study: integrated and comprehensive health services for under five years children with BRL based on Indonesian Health Ministry's standard, was performed from September to November 2016 at respondent's house, posyandu/polindes, Puskesmas Soreang. Data were collected from eighteen respondents (under five years children with BRL's mothers, cadres, midwifes, nutritionist, physician and Head of Puskesmas Soreang) with purposive sampling method and did by in-depth interview. The validation is using data triangulation method. Integrated and comprehensive health services for under five years children with BRL in Puskesmas Soreang consist of promotive and preventive. The promotive service consists of food supplementation and child health education. The preventive service consists of information about underweight, food pattern education, body weight measurement, referral to health provider and supplementary feeding implementation. But, under five years children with BRL's mothers have not been received information of below red line of growth chart and nutrition counseling well from nutritionist/physician yet because the service is still done at the level posyandu/polindes and refferals from posyandu to puskesmas has not been done completely. Curative service has not been done yet in the Puskesmas Soreang based on Indonesian Health Ministry's standard.
\end{abstract}

Keywords : Children Under Five, Integrated and Comprehensive Health Services, Preventive, Promotive, Underweight

Korespondensi:

Lisbeth Maria Laurentia

Fakultas Kedokteran Universitas Padjadjaran

Jl. Raya Bandung-Sumedang km 21 Jatinangor

Mobile : 085692928363

Email : lisbethlaurentia@gmail.com 


\section{Pendahuluan}

Balita Bawah Garis Merah (BGM) adalah balita yang berat badannya berada di bawah garis merah pada Kartu Menuju Sehat (KMS). ${ }^{1}$ Balita BGM perlu dilakukan pemeriksaan lebih lanjut untuk mengetahui status gizi anak, baik gizi kurang atau gizi buruk. ${ }^{2}$ Balita BGM disebabkan oleh kurangnya pemberian nutrisi maupun penyakit infeksi. Dampak kurang nutrisi dalam jangka pendek adalah mudah terkena penyakit infeksi dan dalam jangka panjang adalah gangguan perkembangan kognitif., ${ }^{3}$ Berdasarkan data Profil Kesehatan Provinsi Jawa Barat Tahun 2012, prevalensi balita BGM mencapai 0,9\%, sedangkan balita gizi kurang mencapai $8,57 \%$ dan balita gizi buruk 0,94 \% di Kabupaten Bandung. ${ }^{5}$ Berdasarkan Laporan Tahunan Program Gizi Puskesmas Soreang, prevalensi balita BGM tahun 2014 mencapai $0,79 \%$, sedangkan tahun 2015 mencapai 4,43 \% di wilayah kerja Puskesmas Soreang. ${ }^{6,7}$

Pelayanan terintegrasi dan komprehensif adalah pelayanan yang bersifat menyeluruh dan mengacu pada pelayanan promotif, preventif, kuratif dan rehabilitative secara berkelanjutan. ${ }^{8}$ Berdasarkan Bagan Tatalaksana Anak Gizi Buruk Kementerian Kesehatan Republik Indonesia Tahun 2011, pelayanan balita BGM perlu dilaksanakan secara terintegrasi dan komprehensif, yaitu dengan adanya kerja sama lintas sektor (kader, bidan, petugas gizi dan dokter) dengan cara pelayanan promotif, preventif dan kuratif secara berkelanjutan. ${ }^{2}$ Pelayanan diberikan secara terintegrasi dan komprehensif agar mencapai target dari segi menejemen yaitu berat badan anak dapat mencapai batas normal pada kurva pertumbuhan dan mencegah terjadinya gizi kurang/buruk berulang maupun penyakit infeksi pada anak. ${ }^{2}$ Sampai saat ini belum ada data tentang pelayanan terintegrasi dan komprehensif yang diterima balita berat badan BGM di Puskesmas. Penelitian ini bertujuan untuk mengeksplorasi gambaran pelayanan terintegrasi dan komprehensifberdasarkan standar Kementerian Kesehatan Republik Indonesia serta faktor yang memengaruhi pelayanan yang diterima balita berat badan BGM di Puskesmas Soreang. Penelitian ini diharapkan menjadi sumber informasi dan pertimbangan untuk tatalaksana mengenai pelayanan terintegrasi dan komprehensif yang diterima balita berat badan BGM di Puskesmas Soreang.

\section{Metode}

Penelitian ini menggunakan desain kualitatif dengan 18 subjek, yang terdiri dari 6 orang ibu yang memiliki balita BGM, 5 orang kader, 4 orang bidan desa, seorang petugas gizi, seorang dokter dan seorang Kepala Puskesmas Soreang. Penelitian ini dilakukan mulai dari September sampai November 2016 di rumah responden, posyandu/polindes (Desa Panyirapan, Desa Sekarwangi, Desa Cingcin dan Desa Parungserab) dan Puskesmas Soreang.

Metode sampling menggunakan metode purposive sampling. Kriteria inklusi pada penelitian ini adalah (1) Ibu yang mempunyai balita BGM pada saat pemeriksaan di Posyandu wilayah kerja Puskesmas Soreang periode September tahun 2016. (2) Ibu yang memiliki balita setidaknya berat badan di bawah garis merah lebih dari satu bulan. Kriteria eksklusi pada penelitian ini adalah subjek tidak bersedia mengikuti penelitian.

Pengumpulan data dilakukan dengan wawancara mendalam (in-depth interview). Validasi data menggunakan teknik triangulasi data yaitu sebagai pembanding data dari responden yang berbeda, dalam hal ini dilakukan dengan cara wawancara mendalam kepada lebih dari satu sumber (5 orang kader, 4 orang bidan desa, seorang petugas gizi, seorang dokter dan seorang Kepala Puskesmas Soreang).

Setelah melakukan pengumpulan data, hasil wawancara dibuat transkrip. Hasil transkrip dilanjutkan dengan reduksi data, lalu dilakukan coding serta kategorisasi. Koding adalah suatu proses mengolah informasi menjadi segmensegmen tulisan, lalu membuat kategori dengan istilah khusus. Tujuan koding adalah menjaga konsistensi dalam identifikasi fenomena, menentukan frekuensi munculnya fenomena dan menyusun kategori fenomena. Hasil dari analisis data tersebut akan disajikan berupa teks narasi yang menggambarkan pelayanan terintegrasi dan komprehensif berdasarkan Bagan Tatalaksana Anak Gizi Buruk Kementerian Kesehatan Republik Indonesia Tahun 2011 serta faktor yang memengaruhi pelayanan balita berat badan BGM di Puskesmas Soreang. Penelitian ini merupakan bagian dari payung penelitian Academic Leadership Grant (ALG) di Puskesmas Soreang. Perizinan etik sudah diajukan dan ditandatangani pada 15 Juli 2016 dengan nomor registrasi 0715110901.

\section{Hasil}

Responden pada penelitian ini berjumlah 18 orang, yang terdiri dari 6 orang ibu yang memiliki balita BGM, 5 orang kader, 4 orang bidan desa, seorang petugas gizi, seorang dokter dan seorang Kepala 
Puskesmas Soreang. Wawancara dilakukan di rumah responden, posyandu/polindes dan puskesmas. Berdasarkan wawancara mendalam (in-depth interview),

pelayanan terintegrasi dan komprehensif yang diterima balita BGM di Puskesmas Soreang terdiri dari pelayanan promotif dan preventif. Pelayanan ini merupakan pelayanan lintas sektor yang membutuhkan kerja sama antara kader, bidan, petugas gizi dan dokter.

"Kita di satu sisi bergeraknya gencar di promotif sama preventif, tapi setelah kejadian, ada yang itu, ada balita bawah garis merah yaitu harus tetep perpaduan bukan lintas program lagi tapi lintas sektor. Jadi kalau ada masalah lintas sektor biasanya kita bicarakan di lokmin tapi tingkat kecamatan." R17

Pelayanan promotif di posyandu dilaksanakan dengan pemberian edukasi baik secara langsung (edukasi secara individu/komunitas) maupun tidak langsung. Namun tidak terdapat alat edukasi (plakat atau brosur) yang menjelaskan tentang balita BGM. Pemberian edukasi tentang asupan makanan maupun kesehatan anak diberikan oleh kader dan bidan

"Kalau promotif kan biasanya kita, semua yang di puskesmas ini berkewajiban untuk mempromosikan ya. Nah promosi kita belum begitu. Preventifnya ya dengan penyuluhan, nanti kita memberikan pengetahuan ke kader, nanti kader menyebarkan ke masyarakat, dimana harapannya begitu." - R15

Pelayanan preventif pada balita BGM dimulai dari dilakukan pengukuran tinggi/berat badan dan dipantau setiap bulan di Posyandu. Pemberian edukasi tentang pola makanan dan pola asuh anak diberikan kepada ibu yang memiliki balita BGM oleh kader dan bidan. Apabila balita terdeteksi berat badan di bawah garis merah ataupun tidak naik 2 kali (2T) berturut-turut, kader akan merujuk balita ke bidan/petugas gizi/dokter. Balita tersebut akan diberikan bantuan Pemberian Makanan Tambahan (PMT) berupa susu dan biskuit MPASI, dengan syarat balita BGM berasal dari keluarga miskin, sedangkan balita dengan gizi buruk yang berasal dari keluarga miskin akan diberikan bantuan Pemberian Makanan Tambahan Pemulihan (PMT-P) selama 90 hari, namun penjelasan mengenai pengertian, ciriciri, penyebab, tatalaksana, dampak balita BGM ini belum dijelaskan oleh kader, bidan maupun petugas gizi kepada ibu yang memiliki balita BGM. Lima dari 6 ibu balita BGM tidak tahu tentang definisi, ciri, penyebab BGM. Semua ibu tidak tahu tatalaksana dan dampak BGM. Empat dari $6 \mathrm{ibu}$ berpendapat bahwa BGM merupakan suatu permasalahan, sedangkan 2 orang lainnya ragu-ragu.
"T: Tapi nggak dikasih tau penjelasan tentang bawah garis merah? J: belum, mungkin saya nggak pernah nanyain aja." - R04

"Nggak ya, karena begini kalo disebut BGM suka sakit hati, jadi nggak mau ditimbang. Jadi nanti disebutnya gizi buruk. Jadi disamarkan aja nanti gini gini gini gitu. Jadi itu hati-hati dalam menyampaikan penyuluhan. Nanti kalo ibunya tersinggung, kan anak saya makannya banyak.. Ya memang. Oh mungkin ada penyertanya, coba di periksa ke puskes. Nah baru mau, pas ketemu. Jadi nggak dibilangin BGM, enggak. karena takut begitu bu, kalo gizi buruk nggak dibilangin langsung. Cuma harus dibilang begini gini gini. Takutnya pundung, jadi menyampaikannya perlahan-lahan. Nanti kalau nggak mau ditimbang lagi gimana mau pantaunya." - R09

Pelayanan kuratif hanya dilakukan oleh dokter di puskesmas. Pelayanan kuratif dapat berupa terapi farmakologi dan terapi non farmakologi. Terapi farmakologi atau pemberian obat diberikan apabila balita BGM disertai dengan penyakit penyerta, sedangkan terapi non farmakologi dengan pemberian edukasi tentang tumbuh kembang anak dan pentingnya nutrisi, selain itu dokter akan merujuk kepada ahli gizi untuk diberikan konseling gizi atau dokter spesialis anak apabila anak terdeteksi gizi buruk. Ibu balita BGM belum menerima pelayanan kuratif karena balita belum dibawa ke puskesmas karena permasalahan BGM.

Pelaksanaan pelayanan terintegrasi dan komprehensif yang diterima balita BGM dipengaruhi beberapa faktor, yaitu faktor penerima pelayanan (ibu balita BGM), faktor pemberi pelayanan (kader, bidan, petugas gizi dan dokter) dan faktor fasilitas pendukung. Faktor penerima pelayanan (ibu balita BGM) terdiri dari pengetahuan ibu tentang BGM, pengetahuan ibu tentang asupan nutrisi dan persepsi dalam penanganan balita BGM, tingkat kepatuhan ibu, penerima informasi, tingkat penerimaan ibu, pandangan ibu terhadap hak pelayanan dan kepuasan pelayanan. Faktor pemberi pelayanan terdiri dari ketrampilan edukasi pemberi pelayanan, kerjasama antar lintas sektor dan jumlah tenaga kesehatan/pemberi pelayanan. Faktor fasilitas pendukung terdiri dari alat ukur berat badan, kondisi posyandu, alat edukasi dan dana dari pemerintah (Gambar 1).

Ibu balita BGM berpendapat bahwa tanda di bawah garis merah memang suatu permasalahan, namun pengetahuan ibu tentang balita BGM masih rendah.

"Kalau anaknya BGM karena penyakit atau... Kalau gara-gara penyakit sih masalah." - R02

"Ya sedikit masalah sih, tapi nggak ada efek apa-apa sih ke anak saya." - R04 
Ibu balita BGM belum paham bahwa dalam menangani berat badan kurang harus diberikan makanan tambahanan dan anak tidak bisa dipaksakan dalam pemberian makan. Meskipun telah diberikan edukasi pola makan anak namun persepsi ibu belum sesuai dengan pemberi pelayanan.

"Ya penting, orang tuanya harus telaten, makannya harus dijaga, dikasih makan harus lebih dari 2x. Alhamdulillah ibu ada. Ai makanannya anaknya nggak mau, gimana.." - R05

"Asi aja udah nggak dikasih da nggak mau. Saya beli Frisian baby kan, sebentar maunya lalu nggak mau. Yaudah saya teh nggak dibeli lagi. Kalo ini mah makan jarang, jajan sering. Jajan 15 ribu sehari." - R06

"Yang pertama adalah pemberian pola makan, dari ibunya sendiri ya kebiasaan pola makan, kalau yang saya hadapi di lapangan rata-rata karena ibunya bekerja jadi si anaknya akan dikasih makan saat minta, sedangkan pada usiausia balita memang tidak harus terjadwal tapi kita harus punya pola untuk anak itu sendiri, apalagi pada usia-usia 2 tahun ke bawah, itu asupan nutrisinya harus lebih banyak daripada 2 tahun ke atas. Untuk anak yang 2 tahun ke bawah kecendrungan ibunya saya tanya, "Udah bu?" "Udah, biasanya jajan, malas makan, lagi belajar jalan." Fokusnya biasanya terbagi 2 jadinya. Ke jalan, motorik kasarnya udah mulai aktif, jadi makannya kurang. Terus pemberian makan dari si ibu juga kurang, da dikasih sayuran gamau alesannya ya padahal sama kita udah dikasih tau. Nggak usah sayur yang bentuk sayur, kan bisa di jus, di blender di satuin jadi nggak keliatan sayurnya. Udah dikasih-dikasih motivasi seperti itu sebetulnya, jadi penyebab BGM itu intinya adalah dari cara pemberian makan, terus dari jenisnya itu sendiri istilahnya tidak memenuhi, trus pola hidup sehari-hari termasuk ibunya. Paling itu aja sih BGM. Kalo turunan rata-rata jadi kecil juga bisa sih dok, cuman itu hanya sebagian kecil." - R10

"Ya mungkin sebagai kader mah cuma penyuluhan aja, harus begini-begini gitu ya, ya alhamdulilah ya kalo si ibunya mau menerima, trus diterapkan di rumah gitu... Ya penyuluhan mengenai makanan yang bergizi, gitu ya. Cara ngasih makan kalo bayi teh jangan beli dari jajanan, kan setiap pagi katanya beli bubur aja, meskipun di bubur kan ada sayurnya, tapi itu doang kan airnya aja... Trus ayamnya ada, tapi sayurnya mending bikin sendiri lah, kebanyakan disini beli bubur aja, coba kalo dibikin sendiri kan lebih bersih, kan tidak pakai pecin." - R09

Semakin baik tingkat pengetahuan ibu akan pentingnya balita BGM, makan semakin tinggi pula tingkat kepatuhan ibu dalam melaksanakan informasi yang diberikan kader maupun bidan.

"Paling kita, hm, udah kasih penyuluhan ke ibunya, suruh datang ke petugas gizi. Nggak tau ibunya dateng nggak. Kadang-kadang kan suka disuruh ke puskesmas, nggak tau datang atau nggak." - R12

Tingkat pengetahuan ibu akan lebih baik apabila ibu menerima informasi secara langsung dari kader maupun bidan. Informasi yang diberikan secara langsung akan diterima lebih akurat dan dapat menyamakan persepsi antara kedua pihak.

"Kalo di RW 14 kan udah jalan kan kelas balitanya. Seperti itu diwawancara ke ibunya, tapi kalo dianter sama neneknya rata-rata kurang ini ya. Maksudnya untuk informasinya kurang akurat, karena neneknya biasanya nggak tau cenah. Kalo sama mamanya ya sama mamanya, kirang terang. Memang harus sama ibunya, cuma rata-rata kalo ke posyandu terkadang sama neneknya/bibinya/tetangga." - R10

Apabila terdapat persamaan persepsi dan pengetahuan tentang BGM antara ibu dan pihak pemberi pelayanan, serta penyampaian informasi diberikan dengan benar dan jelas, maka informasi akan diterima tanpa menyakiti hati penerima pelayanan.

"Nah itu dia, nggak punya pengetahuan dia kan. Kalo bilang BGM kan nerima, tapi kalau bilang gizi buruk dia nggak terima. Kalau BGM dia nerima cuma itu aja, cuma kita mungkin kurang juga memberikan di posyandu. Itu kan kadang-kadang pelayanan kayak kurang ya. Kadang datang, nimbang, pulang. Jadi pengetahuan buat mereka juga kurang. Kayak saya juga nggak semua posyandu tiap bulan saya kunjungi kan. Paling sebulan 6-10x. Itu pun kalau satu bulan saya nggak full kegiatannya." - R15

"Iya takutnya sakit hati ya.. Kok anak saya disebut kurang gizi gitu. Jadi takut ibunya kurang terima, biasanya agak marah kalau disebut gitu." $-\mathrm{R} 11$

Menurut pandangan ibu balita BGM, pelayanan yang diberikan semestinya tidak hanya berupa edukasi.

"T: Jadi ibu seenggaknya pengen dapet informasi ya? Selain informasi mungkin apalagi bu? J: Apaya.. Bantuan mungkin. T: Bantuannya berupa apa bu? J: Vitamin yang baguslah, apa gitu.." - R03

Ibu balita BGM merasa belum puas dengan pelayanan yang diberikan karena mereka berpendapat semestinya diberikan bantuan lain.

"Kalau buat segitu mah puas aja kalau tentang edukasinya mah, kalau yang lain-lainnya mah nggak tau, orang belum ada..” - R03

"Pelayanan posyandu ya gitu-gitu aja. Gimana ya.. Dibilang puas nggak.. Hm.. Dibilang nggak 
takutnyagimanagitu.Paling biasa-biasaaja."-R04

Cara penyampaian informasi juga harus diperhatikan oleh pemberi pelayanan khususnya kader dan bidan, karena pihak tersebut yang paling dekat dengan ibu yang menerima pelayanan. Oleh karena itu, perlu ditingkatkan pengetahuan dan keterampilan kader dan bidan dalam menyampaikan edukasi. Tiga dari 5 kader belum tahu dampak balita BGM, sedangkan dari 4 bidan terdapat 1 bidan belum tahu dampak BGM. Selain itu, petugas gizi juga semestinya diberikan pelatihan juga agar dapat memberikan informasi kepada pihak-pihak pemberi pelayanan maupun ibu yang memiliki balita BGM. Namun, keterbatasan dana dalam penyelenggaraan pelatihan merupakan salah satu kendala.

"Iya. Biar kadernya punya pengetahuan yang sama.. Tapi kekurangan dana lagi, yang namanya pelatihan kan perlu dana. Jadi kita nggak bisa juga melaksanakan semaunya kita. Kalau ada dana kita bisa laksanakan, kalau nggak ada dananya? Dari mana?" - R15

"Banyak sebetulnya ya, pasti kita selalu berusaha untuk meningkatkan mutu, salah satunya di gizi buruk ini, tapi yang saya lihat sih kalau perencanaan sudah agak lumayan, ada usaha. Mungkin masalah dana harus dibesarkan lebih gampang lagi. Ya ahli gizinya pun; dia juga memberikan dan untuk menigkatkan kemampuan ahli gizinya kita harus trainingkan lagi, jadi selalu ada refreshing baik itu kadernya udah tapi yang ahli gizinya belum. Pelatihan lagi terusmenerus."- R17

Pemberian pelayanan dalam permasalahan balita BGM bukan hanya tugas tenaga kesehatan, melainkan kerjasama lintas sektor. Bagan Tatalaksana Anak Gizi Buruk Kementerian Kesehatan Republik Indonesia Tahun 2011 belum diketahui oleh kader. Oleh karena itu, dibutuhkan persamaan persepsi antara seluruh pemberi pelayanan.

"Belum terlalu apa ya namanya.. Hm, maksudnya.. Kita ada anak gizi buruk nih, mbok ya bareng-bareng gitu kasih taunya, itu teh mestinya bagaimana.. Jadi pengetahuan kita mesti sama, persepsinya harusnya sama. Kita belum menjajakan sampai kesana sih. "- R15

Jumlah tenaga kesehatan yang terbatas berpengaruh dalam pelaksanaan pelayanan terutama dalam memberikan edukasi maupun konseling kepada ibu balita BGM. Tenaga kesehatan yang berperan terdiri dari satu bidan tiap desa, satu petugas gizi (yang bertanggung jawab atas 6 desa) dan dua dokter di Puskesmas Soreang. Selain itu, petugas gizi memiliki rangkap tugas di puskesmas sehingga fokus dalam pelayanan tidak maksimal.

"Kalau dari pemberi pelayanan cukup sih, itu aja kita mungkin. Ya itu tadi, kurang swadaya karena tenaga terbatas. Untuk ke semua desa terakses dengan cepat, walaupun sekarang komunikasi sudah canggih, nggak semua orang juga punya komunikasi yang sama." - R15

Faktor lain yang mempengaruhi pelayanan berupa fungsi alat ukur yang baik untuk penimbangan maupun pengukuran tinggi badan di posyandu agar mendapatkan hasil yang akurat. Selain itu, bangunan posyandu yang mumpuni juga memengaruhi agar masyarakat semakin tertarik untuk melakukan penimbangan.

"Kalo selama ini dari posyandu keluh kesah nggak ada, cuma mungkin untuk timbangannya sendiri beberapa RW sudah jelek, tapi beberapa sudah dapat bantuan juga. Karena itu tadi ya dok, terbentur program, jadi nggak bisa semuanya diganti baru. Ya kalo ada bantuan dari pihak lain boleh lah ya, supaya kita bisa dengan akurat menentukan ini bayi BGM atau bukan.. trus untuk yang lainnya adalah belum ada lah yang posyandu belum bangunan sendiri. Karena terbentur tanahnya. Jadi kalo di Panyirapan ada beberapa RW yang belum punya bangunan posyandu sendiri karena terbentur lahan yang tidak ada. Kadang di rumah kader/warung, kurang menarik lah kadang juga menjadi alasan ibu-ibu. "Kenapa nggak ditimbang?" "Da di warung timbangnya, geura budak ditimbang, abdi jajan". Harapan saya untuk Desa Panyirapan, semua posyandu bisa memiliki gedung sendiri. Dengan sarana dan prasarana yang dilengkapi. Terutama juga untuk SDMnya, ibu kadernya bisa ditambah, jadi bisa jadi motivator sendiri ya untuk masyarakatnya." - R10

Alat edukasi seperti food model juga diperlukan dalam membantu konseling gizi kepada ibu balita BGM.

"Ituyang kitalagiusulin, kankitapuskesmasnya baru di bangun ya.. Di dinas dikirain Soreang udah dapet, padahal belum jadi kita nggak punya alat, food model, gitu-gitu belum punya." - R15

Skema pelayanan terintegrasi dan komprehensif yang diterima balita BGM serta faktor yang memengaruhi pelayanan.

\section{Pembahasan}

Pelayanan terintegrasi dan komprehensif balita BGM di Puskesmas Soreang terdiri dari pelayanan promotif dan preventif. Pelayanan promotif berupa edukasi makanan dan kesehatan anak. Edukasi telah diberikan pihak puskesmas dengan harapan meningkatkan pengetahuan ibu, namun belum diterapkan oleh ibu balita BGM.

Penelitian menunjukkan bahwa intervensi edukasi tentang pemberian makanan tambahan kepada orangtua mampu memperbaiki 


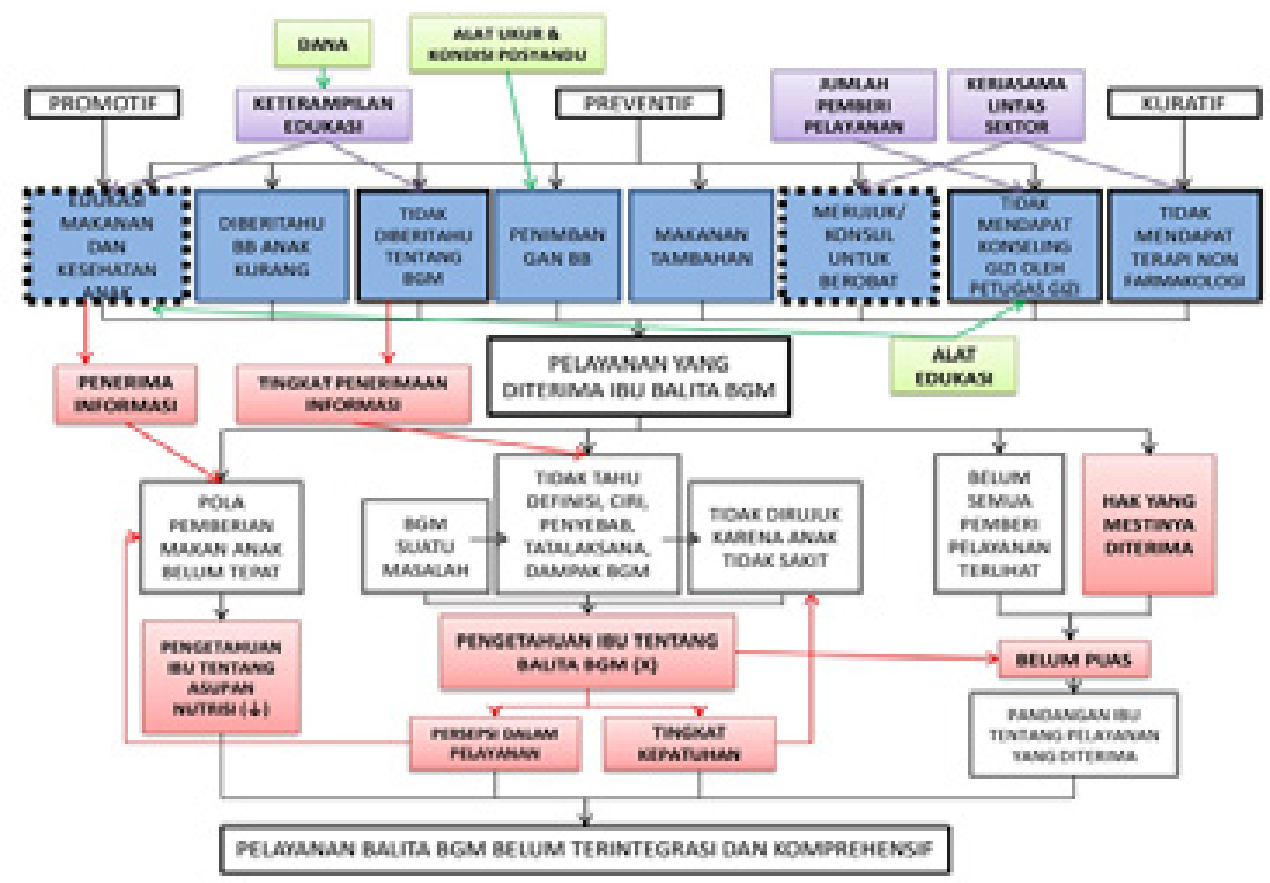

Keterangan:

1.Faktor yang mempengaruhi pelayanan: Penerima pelayanan (kotak merah muda), Pemberi pelayanan (kotak ungu), Fasilitas pelayanan (kotak hijau).

2.Pelayanan-pelayanan yang diterima ibu balita BGM (kotak biru); garis biru (sudah terapkan), garis putus-putus (belum dilaksanakan maksimal), garis hitam (belum dilaksanakan).

\section{Gambar 1 Skema Pelayanan Terintegrasi dan Komprehensif Balita BGM serta Faktor yang Memengaruhi Pelayanan di Puskesmas}

pertumbuhan balita.9, 10 Oleh karena itu perlu dilakukan peningkatan kualitas dan kuantitas edukasi pemberian makanan dan kesehatan anak.

Pelayanan preventif balita BGM terdiri dari edukasi pola makanan dan status nutrisi berat badan anak kurang, pengukuran tinggi/berat badan berkala, PMT dan PMT-P bagi keluarga miskin serta rujukan untuk berobat. Makanan tambahan perlu diberikan karena terbukti meningkatkan berat badan anak. ${ }^{11-13}$ PMT memang diutamakan untuk keluarga miskin tetapi edukasi penambahan pola makan harus diberikan kepada semua ibu. Dari hasil penelitian, 4 dari 6 ibu balita BGM tahu bahwa BGM merupakan suatu permasalahan, tetapi 5 dari 6 ibu tidak tahu definisi, ciri, penyebab BGM. Semua ibu tidak tahu tatalaksana dan dampak BGM. Oleh karena itu, ibu tidak sadar bahwa BGM benar-benar merupakan suatu tanda permasalahan tumbuh kembang anak. Hal tersebut juga berpengaruh terhadap penanganan yang diberikan ibu yaitu kurangnya pemberian pola makan dan anak tidak dibawa ke puskesmas. Ibu balita BGM seharusnya mendapatkan edukasi BGM dan konseling gizi dari petugas gizi/dokter, sehingga ibu akan lebih paham mengenai BGM dan gizi. ${ }^{14}$

Pelayanan kuratif balita BGM di puskesmas belum diterima karena balita belum dibawa berobat dengan persoalan berat di bawah garis merah. Pelayanan kuratif harus tetap dijalankan untuk balita BGM. $^{2}$ Meskipun penyebab balita BGM tidak selamanya karena penyakit infeksi, namun pola asuh dari orangtua sangat berpengaruh. ${ }^{15}$ Oleh karena itu, balita BGM tetap mendapatkan pelayanan kuratif secara nonfarmakologi dengan pemberian edukasi pola asuh untuk orangtua balita BGM.

Implementasi pelayanan terintegrasi dan komprehensif untuk balita BGM di Puskesmas Soreang dipengaruhi oleh tiga faktor yaitu faktor penerima pelayanan, faktor pemberi pelayanan dan faktor fasilitas pendukung. Salah satu faktor penerima pelayanan adalah rendahnya tingkat pengetahuan ibu tentang asupan nutrisi. Apabila ibu memiliki pengetahuan yang cukup tentang asupan nutrisi maka berat badan anak lebih baik dibandingkan ibu yang berpengetahuan rendah. ${ }^{16}$ Semakin baik pengetahuan orangtua, semakin baik pula asupan nutrisi anak. ${ }^{17}$ Salah satu faktor pemberi pelayanan adalah kurangnya 
ketrampilan petugas dalam memberi edukasi. Semakin baik ketrampilan petugas, semakin efektif edukasi yang diberikan. ${ }^{18}$ Keterampilan edukasi pemberi pelayanan juga mempengaruhi efektifitas pemberian makanan sehat oleh orangtua untuk anak. ${ }^{19}$ Kedua contoh faktor tersebut memengaruhi pelayanan yang diterima balita BGM belum efektif baik secara terintegrasi dan komprehensif.

Dari hasil penelitian didapatkan bahwa alur pelayanan seperti dalam Bagan Tatalaksana Anak Gizi Buruk Kementerian Kesehatan Republik Indonesia Tahun 2011 belum terlaksana sepenuhnya. Pelayanan balita BGM belum terintegrasi disebabkan kerjasama lintas sektor belum berjalan dengan baik, karena pelayanan ini seharusnya diberikan dari berbagai multidisiplin. ${ }^{20}$ Persepsi pemberi pelayanan untuk tatalaksana BGM belum sama. Pelayanan balita BGM belum komprehensif karena pelayanan masih dilaksanakan di tingkat posyandu/polindes sehingga pelayanan yang diterima hanya pelayanan promotif dan preventif. Pelayanan balita BGM seharusnya diberikan sampai tingkat puskesmas seperti dalam Bagan Tatalaksana Anak Gizi Buruk Kementerian Kesehatan Republik Indonesia Tahun 2011, sehingga balita BGM menerima pelayanan kuratif setidaknya terapi non-farmakologi dari dokter yaitu pemberian edukasi tentang tumbuh kembang anak dan pentingnya nutrisi, selain itu dokter akan merujuk kepada ahli gizi untuk diberikan konseling gizi atau dokter spesialis anak apabila anak terdeteksi gizi buruk. ${ }^{2}$ Balita BGM harus diperiksa ke dokter karena dokter memiliki pengetahuan mumpuni untuk melihat kondisi anak maupun memberi edukasi kepada ibu. Oleh karena itu, diperlukan kerjasama dan persamaan persepsi antara masyarakat dan petugas kesehatan, khususnya kader dan bidan dalam mendampingi ibu balita BGM untuk memeriksakan balita BGM ke Puskesmas.

Dalam pelayanan kasus BGM tidak cukup apabila ditangani oleh satu bidan tiap desa dan satu petugas gizi di puskesmas. Hasil pelayanan akan lebih baik apabila tenaga kesehatan lebih banyak karena cakupan wilayah yang cukup luas. Oleh karena itu, peneliti merekomendasi Dinas Kesehatan Kabupaten Bandung dan Puskesmas Soreang untuk menambah jumlah tenaga kesehatan dan perbaikan kualitas dengan meningkatkan kerjasama, pengetahuan tentang BGM dan persamaan persepsi antar sektor pemberi pelayanan. Puskesmas Soreang perlu mensosialisasikan dan menerapkan alur pelayanan Bagan Tatalaksana Anak Gizi Buruk Kementerian Kesehatan Republik Indonesia Tahun 2011. Selain itu puskesmas juga perlu meningkatkan pengetahuan ibu dengan memberikan edukasi tentang BGM dan konseling gizi. Persamaan persepsi tentang BGM merupakan hal terpenting antara pemberi dan penerima pelayanan agar tatalaksana balita BGM terlaksana dengan baik.

Data balita BGM di Puskesmas Soreang pada tahun 2014 adalah $0,79 \%$, sedangkan tahun 2015 mencapai $4,43 \%{ }^{6,7}$ Kenaikan presentase yang signifikan disebabkan oleh pendataan balita BGM yang masih belum mumpuni. Oleh karena itu, Puskesmas Soreang perlu memperbaiki sistem pencatatan dan pelaporan data agar memiliki data yang akurat. Dengan prevalensi balita BGM 4,43\% pada tahun 2015 dan tidak ada perubahan dalam peningkatan pelayanan, maka kemungkinan untuk menekan angka prevalensi semakin kecil.

Keterbatasan dalam penelitian ini adalah penelitian kualitatif merupakan hal yang baru bagi peneliti sehingga permasalahan dalam penelitian belum dikupas sepenuhnya karena keterbatasan waktu dan kemampuan peneliti dalam menggali informasi.

Dari penelitian ini dapat ditarik kesimpulan bahwa pelayanan balita BGM yang diterima berupa pelayanan promotif dan preventif di posyandu/polindes. Pelayanan kuratif di puskesmas untuk balita BGM seperti dalam Bagan Tatalaksana Anak Gizi Buruk Kementerian Kesehatan Republik Indonesia Tahun 2011 belum berjalan.

\section{Ucapan Terima Kasih}

Penulis mengucapkan terima kasih kepada Prof. Dr. Dany Hilmanto, dr. $\operatorname{SpA}(\mathrm{K})$ yang telah memfasilitasi penelitian ini melalui proyek penelitian dengan dana yang berasal dari Academic Leadership Grant Universitas Padjadjaran.

\section{Daftar Pustaka}

1. Kementerian Kesehatan Republik Indonesia. Panduan penyelenggaraan pemberian makanan tambahan pemulihan gizi kurang dan ibu hamil kek (Bantuan Operasional Kesehatan). 2012 (diunduh 24 Februari 2016) tersedia dari: http://gizi.depkes.go.id.

2. Kementrian Kesehatan Republik Indonesia. Bagan tatalaksana anak gizi buruk buku I. Jakarta: Departemen Kesehatan; 2011.

3. Sandjaja, Poh BK, Rojroonwasinkul N, Le Nyugen BK, Budiman B, Ng LO, et al. Relationship between anthropometric indicators and cognitive performance in 
Southeast Asian school-aged children. The British journal of nutrition. 2013;110 Suppl 3:S57-64.

4. Katona P, Katona-Apte J. The interaction between nutrition and infection. Clinical infectious diseases : an official publication of the Infectious Diseases Society of America. 2008;46(10):1582-8.

5. Dinas Kesehatan Kota Bandung. Profil kesehatan kota Bandung tahun 2012. 2012.

6. Puskesmas Soreang. Laporan tahunan program gizi Puskesmas Soreang tahun 2014. 2015.

7. Puskesmas Soreang. Laporan tahunan program gizi Puskesmas Soreang tahun 2015. 2016.

8. World Health Organization. Integrated health services - what and why? 2008;1.

9. Shi L, Zhang J, Wang Y, Caulfield LE, Guyer B. Effectiveness of an educational intervention on complementary feeding practices and growth in rural China: a cluster randomised controlled trial. Public health nutrition. 2010;13(4):556-65.

10. McGowan L, Cooke LJ, Gardner B, Beeken RJ, Croker H, Wardle J. Healthy feeding habits: efficacy results from a clusterrandomized, controlled exploratory trial of a novel, habit-based intervention with parents. The American journal of clinical nutrition. 2013;98(3):769-77.

11. Huybregts L, Houngbe F, Salpeteur C, Brown $\mathrm{R}$, Roberfroid D, Ait-Aissa M, et al. The effect of adding ready-to-use supplementary food to a general food distribution on child nutritional status and morbidity: a clusterrandomized controlled trial. PLoS medicine. 2012;9(9):e1001313.

12. Karakochuk C, van den Briel T, Stephens $\mathrm{D}$, Zlotkin S. Treatment of moderate acute malnutrition with ready-to-use supplementary food results in higher overall recovery rates compared with a corn-soya blend in children in southern Ethiopia: an operations research trial. The American journal of clinical nutrition. 2012;96(4):911-6.

13. de Pee S, Bloem MW. Current and potential role of specially formulated foods and food supplements for preventing malnutrition among 6- to 23-month-old children and for treating moderate malnutrition among 6- to 59-month-old children. Food and nutrition bulletin. 2009;30(3 Suppl):S434-63.

14. Lina N, Hidayanti L. Analisis dampak konseling gizi terhadap peningkatan pengetahuan gizi ibu yang memiliki balita gizi kurang. Jurnal Kesehatan Komunitas Indonesia Vol. 2015;11(1).

15. Abubakar A, Holding P, Mwangome M, Maitland K. Maternal perceptions of factors contributing to severe under-nutrition among children in a rural African setting. Rural and remote health. 2011;11(1):1423.

16. Moestue H, Huttly S. Adult education and child nutrition: the role of family and community. Journal of epidemiology and community health. 2008;62(2):153-9.

17. Sausenthaler S, Kompauer I, Mielck A, Borte $\mathrm{M}$, Herbarth O, Schaaf B, et al. Impact of parental education and income inequality on children's food intake. Public health nutrition. 2007;10(1):24-33.

18. Sunguya BF, Poudel KC, Mlunde LB, Shakya $P$, Urassa DP, Jimba M, et al. Effectiveness of nutrition training of health workers toward improving caregivers' feeding practices for children aged six months to two years: a systematic review. Nutrition journal. 2013;12:66.

19. Black C, Lawrence W, Cradock S, Ntani G, Tinati T, Jarman M, et al. Healthy conversation skills: increasing competence and confidence in front-line staff. Public health nutrition. 2014;17(3):700-7.

20. Fairchild RM, Morgan MZ. Delivering multidisciplinary public health in action the Cardiff food strategy case study. Public health nutrition. 2007;10(1):42-8. 